Our study has several limitations. Answering questions about a sensitive topic on the telephone can be difficult, a questionnaire with a fixed choice of answers prevented doctors from qualifying or justifying their responses, and we lacked detailed information about doctors who did not respond.

Previous studies found similar patterns, but the French counterparts to Italian general practitioners and US oncologists were more in favour of legalising euthanasia. ${ }^{3}$ Our findings contradict the argument that opinions on euthanasia are related to cultural differences in English speaking countries; comparative studies are needed. ${ }^{2}$ In France, the support shown for euthanasia may be due to a lack of professional knowledge on palliative care. ${ }^{5}$ Improving such knowledge would improve end of life care and may also clarify the debate over euthanasia.

We thank H Granier, Y Obadia, B Planchet-Barraud, F Ravallec, M Rotily, and O Priolo.
Contributors: MKB, HP, JML, RF, and AG designed the survey and reviewed and improved the paper. JPM and PP-W did the statistical analysis and wrote the paper. PP-W is guarantor.

Funding: Departmental Centre of Private Health Professionals (grant from the fund for improving ambulatory care), Assistance Publique-Hôpitaux de Marseilles (within the hospital programme for clinical research), and Cancer Research Foundation (ARC).

Competing interests: None declared.

Ethical approval: Not needed.

Hermsen MA, ten Have HA. Euthanasia in palliative care journals. J Pain Symptom Manage 2002;23:517-25.

2 Seale C. Changing patterns of death and dying. Soc Sci Med 2000;51:917-30.

3 Grassi L, Magnani K, Ercolani M. Attitudes toward euthanasia and physician-assisted suicide among Italian primary care physicians.J Pain Symptom Manage 1999;17:188-96.

4 Emanuel EJ, Fairclough D, Clarridge BC, Blum D, Bruera E, Penley WC, et al. Attitudes and practices of US oncologists regarding euthanasia and physician-assisted suicide. Ann Intern Med 2000;133:527-32.

Ben Diane MK, Pegliasco H, Galinier A, Lapiana JM, Favre R, Peretti-Watel P, et al. Prise en charge des malades en fin de vie en médecine générale et spécialisée [Terminal care of patients by the general practitioner and the specialsee [Ten che

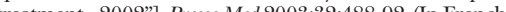

(Accepted 28 July 2003)

\title{
Case fatality rates for meningococcal disease in an English population, 1963-98: database study
}

\author{
Michael J Goldacre, Stephen E Roberts, David Yeates
}

Unit of Health-Care Epidemiology, Department of Public Health, University of Oxford, Oxford OX3 7LF

Michael J Goldacre professor of public health

Stephen E Roberts statistician

David Yeates computer scientist

Correspondence to: M Goldacre michael.goldacre@ dphpc.ox.ac.uk

BMJ 2003;327:596-7

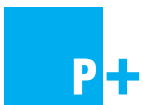

Tables for specific age groups are on bmi.com
Meningococcal septicaemia and meningitis are common causes of death in children and young adults. In fatal cases, the time from onset to death is often short. We analysed case fatality rates for meningococcal disease between 1963 and 1998 to determine whether they have decreased.

\section{Methods and results}

We used data on meningococcal disease from the Oxford record linkage study database, which includes anonymised statistical abstracts of records of admission to hospital and death certificates in a defined population of 0.35 million people from 1963, 0.9 million from 1966, 1.9 million from 1974, and 2.5 million from 1987 to 1998 . We calculated incidence of menin- gococcal disease and case fatality rates and assessed the significance of trends over time with logistic regression.

From 1963 to 1998, 1223 people had a record of admission to hospital for meningococcal meningitis or meningococcal septicaemia and 25 for other diagnoses-mainly meningitis or septicaemia without specification of an organism and a death certificate that specified meningococcal disease. The median age of these 1248 was 6 years; $255(20 \%)$ were $<1$ year old, 422 (34\%) were 1-9 years old, 279 (22\%) were $10-19$ years old, $290(23 \%)$ were $\geq 20$ years old, and the ages of two were unknown; 116 died within 30 days and five more within 365 days of admission.

Analysis of the database showed that a further 25 people had died from meningococcal disease. Fifteen

Cases of meningococcal disease ${ }^{*}$ from the $0 x f o r d$ record linkage study database, number of deaths within 30 days and case fatality rate per 100 000, 1963-98

\begin{tabular}{|c|c|c|c|c|c|c|c|}
\hline \multirow[b]{2}{*}{ Time period } & \multicolumn{3}{|c|}{ Cases admitted to hospital } & \multicolumn{4}{|c|}{ All cases } \\
\hline & $\begin{array}{l}\text { No of } \\
\text { cases }\end{array}$ & $\begin{array}{l}\text { No of } \\
\text { deaths }\end{array}$ & $\begin{array}{c}\text { Case fatality rate } \\
(95 \% \mathrm{Cl})\end{array}$ & $\begin{array}{l}\text { No of } \\
\text { cases }\end{array}$ & $\begin{array}{c}\text { Incidence per } 100000 \\
\text { population }(95 \% \mathrm{Cl})\end{array}$ & $\begin{array}{l}\text { No of } \\
\text { deaths† }\end{array}$ & $\begin{array}{l}\text { Case fatality rate } \\
(95 \% \mathrm{CI})\end{array}$ \\
\hline $1963-8$ & 41 & 5 & $12.2(2.2$ to 22.2$)$ & 42 & $1.23(0.86$ to 1.60$)$ & 6 & 14.3 (3.7 to 24.9$)$ \\
\hline 1969-73 & 72 & 6 & 8.3 (1.9 to 14.7$)$ & 74 & 1.72 (1.33 to 2.11$)$ & 8 & 10.8 (3.7 to 17.9$)$ \\
\hline $1974-8$ & 108 & 12 & 11.1 (5.2 to 17.0$)$ & 111 & 1.24 (1.01 to 1.47$)$ & 15 & 13.5 (7.2 to 19.9$)$ \\
\hline 1979-83 & 113 & 11 & 9.7 (4.3 to 15.2$)$ & 113 & 1.09 (0.89 to 1.29$)$ & 11 & 9.7 (4.3 to 15.2$)$ \\
\hline 1984-8 & 147 & 16 & 10.9 (5.8 to 15.9$)$ & 152 & 1.33 (1.12 to 1.54$)$ & 21 & $13.8(8.3$ to 19.3$)$ \\
\hline 1989-93 & 303 & 25 & 8.3 (5.2 to 11.3$)$ & 308 & 2.40 (2.13 to 2.67 ) & 30 & 9.7 (6.4 to 13.1$)$ \\
\hline 1994-8 & 464 & 41 & 8.8 (6.3 to 11.4$)$ & 473 & 3.55 (3.23 to 3.87 ) & 50 & 10.6 (7.8 to 13.3$)$ \\
\hline 1963-98 & 1248 & 116 & 9.3 (7.7 to 10.9$)$ & 1273 & 1.97 (1.86 to 2.07$)$ & 141 & 11.1 (9.4 to 12.8$)$ \\
\hline$P$ value for trend $\neq$ & & & 0.31 & & $<0.001$ & & 0.28 \\
\hline
\end{tabular}

${ }^{*}$ International Classification of Diseases, 9th revision, code 036 and 10th revision code A39.

tIncludes 25 people who died outside hospital or who had no record of hospital admission.

$\ddagger P$ values refer to the change in annual rates 1963-98 from logistic regression modelling. Visual inspection of the annual incidence and further modelling showed little change in incidence during 1963-88 $(P=0.10)$ and a significant increase during 1989-98 $(P<0.001)$. 
died in a hospital in the region but had no record of admission; they had probably been brought in dead or died soon after arrival at hospital without a formal admission. Ten had died at residential addresses. The median age of the 25 was 16 years, and 11 (44\%) were aged at least 20 years. Of all 146 people who died, 25 (17\%) died without admission to hospital, 41 (28\%) died on the day of admission, and 40 (27\%) died the day after admission.

Incidence has risen substantially in recent years (table). Case fatality rates have not significantly declined over time $(\mathrm{P}=0.31$ for cases admitted to hospital, and $\mathrm{P}=0.28$ for all cases). We found no significant trends in case fatality rates within individual age groups (see tables on bmj.com). For those admitted to hospital, case fatality rates at 30 days were similar in the teaching hospital $(8.9 \%$; $95 \%$ confidence interval $5.6 \%$ to $12.2 \%)$ and non-teaching hospitals $(9.4 \% ; 7.6 \%$ to $11.3 \%$ ), and in males and females.

\section{Comment}

Case fatality rates for meningococcal disease in the Oxford region have not fallen since the late 1960s. Others have also reported no recent reduction in case fatality rates in population based studies, ${ }^{1-3}$ although recent declines in a specialist paediatric unit have been described. ${ }^{4}$ In our study, a relatively high percentage of people who died outside hospital, or on arrival, were adults and perhaps had been less closely observed than children in their illness outside hospital. Our case fatality rate of $11 \%$ is the same as that found in a study based on multiple source case ascertainment and case note review in an adjacent health region in 1969-74. ${ }^{4}$ In that study, $22 \%$ of all deaths, compared to $17 \%$ in this study, occurred without admission to hospital or in people who were dead on arrival. ${ }^{5}$

The time from onset to death is usually rapid. This, and the fact that death rates have not declined, emphasises the need for vigilance in making the diagnosis and the importance of prevention through immunisation and, when appropriate, chemoprophylaxis for contacts.

Contributors: MJG designed the study and wrote the manuscript. SER did the analyses and wrote the manuscript. DY programmed the Oxford record linkage study database. MJG and SER are guarantors.

Funding: SER receives funding from the Department of Health as part of its funding for the National Centre for Health Outcomes Development; and the Unit of Health-Care Epidemiology is funded by the Research and Development Directorate of the Department of Health and Social Care (South). The views expressed in this paper are those of the authors and not necessarily those of the Department of Health. Competing interests: None declared.

1 Wylie PA, Stevens D, Drake W III, Stuart J, Cartwright K. Epidemiology and clinical management of meningococcal disease in west Gloucestershire: retrospective, population based study. BMJ 1997;315:774-9.

2 Sorensen HT, Steffensen FH, Schonheyder HC, Nielsen GL, Hansen I, Madsen KM, et al. Trend in incidence and case fatality of meningococcal disease over 16 years in northern Denmark. Eur J Clin Microbiol Infect Dis disease over 16 ye $17: 690-4$.

3 Booy R, Habibi P, Nadel S, de Munter C, Britto J, Morrison A, et al. Meningococcal Research Group. Reduction in case fatality rate from meningococcal disease associated with improved healthcare delivery. Arch Dis Child 2001;85:386-90.

4 Goldacre MJ. Acute bacterial meningitis in childhood: incidence and mortality in a defined population. Lancet 1976;1:28-31.

Goldacre MJ. Acute bacterial meningitis: where do children die? Int J Epidemiol 1976;5:343-7.

(Accepted 16June 2003)

\title{
Prophylaxis for venous thromboembolism during treatment for cancer: questionnaire survey
}

\author{
C C Kirwan, E Nath, G J Byrne, C N McCollum
}

Venous thromboembolism is common in patients with cancer and is often the cause of death. ${ }^{1}$ Patients receiving treatment for cancer are at even greater risk of thromboembolism. Thromboembolism occurs in 5\% of patients receiving chemotherapy for early breast carcinoma, ${ }^{2}$ and up to $17.6 \%$ of patients receiving chemotherapy for metastatic breast disease are affected. ${ }^{3}$ Patients with node-negative breast cancer taking tamoxifen were six times more likely to develop venous thromboembolism. ${ }^{4}$

Adjuvant use of tamoxifen carries a relative risk of 1.22 compared with no treatment. Combining methods of treatment further increases the risk of thromboembolism. Chemotherapy with tamoxifen increases risk by 3.5 times compared with chemotherapy alone, ${ }^{5}$ and preoperative radiotherapy for rectal carcinoma doubles the postoperative risk of venous thrombosis. ${ }^{5}$ Low doses (1 mg) of warfarin throughout chemotherapy for metastatic breast cancer are associated with a relative risk reduction of $85 \%$ with no increase in serious bleeding complications. ${ }^{1}$

\section{Participants, methods, and results}

We sent a postal questionnaire to all oncologists in northern England, identified by internet search and in the Medical Directory 2002. We used a scoring system to establish specialty, main type of cancer treated, main method of treatment (chemotherapy, hormone therapy, or radiotherapy), and current prophylaxis practice and estimate of risk of venous thrombembolism.

Of the 123 responses to the 166 questionnaires we sent, 106 (64\%) were acceptably completed. Half the oncologists (56) specialised in clinical oncology, 31 in medical oncology, seven in surgery, five in gynaecological oncology, five in paediatrics, one in urology, and one in radiology. We have no information about the specialties of oncologists who did not respond. The most common treatment was chemotherapy, used by $41(39 \%)$ oncologists; $10(9 \%)$ used hormone therapy and $44(42 \%)$ used radiotherapy. The oncologists treated many types of tumour. 